\title{
Política de Assistência Social e a posição da família na política social brasileira
}

\author{
MARTA SILVA CAMPOS* \\ REGINA CÉLIA TAMASO MIOTO**
}

Resumo: $O$ artigo discute o lugar que a família ocupa nos sistemas de proteção social. Considera três propostas analíticas relativas ao tema em pauta: a família do provedor masculino, o "familismo" e a família no Estado de Bem-Estar Social de orientação social-democrata. Analisa a posição da família em nossa política social, mediante exame de elementos legais e operacionais e destaca sua relevância na política de assistência da sociedade brasileira. Considerando as tendências de redução da "capacidade protetora" do grupo familiar, devido a transformações demográficas e culturais e ao empobrecimento da população, sugere regressividade da política social vigente já que a expectativa de solidariedade da sociedade passa a centrar-se irrealisticamente na família.

Palavras-chave: Assistência social, família, política social.

\begin{abstract}
The article discusses the place occupied by the family in the social protection systems. It considers three analytical proposals related to the present subject: the male breadwinner family, the "familism" and the family in the social democrat oriented Welfare State. It analyses the position of the family in our social policy, through the examination of legal and operational elements, and highlights its relevance in the Brazilian social assistance policy. Considering the reduction trends in the "protective capacity" of the familial group due to demographic and cultural transformations and to the impoverishment of the population, it suggests the regressiveness of the current social policy, since the expectation of solidarity of the society becomes centered unrealistically around the family.
\end{abstract}

Keywords: Social Assistance, family, social policy

*Professora da Faculdade de Serviço Social e do Programa de Estudos Pós- Graduados em Serviço Social da PUC-SP. E-mail: martaxx-2000@yahoo.com

${ }^{* *}$ Professora do Departamento de Serviço Social da Universidade Federal de Santa Catarina.

E-mail: mioto@cse.ufsc.br 


\section{Introdução}

O recente lançamento do Programa Fome Zero pelo novo governo federal teve o poder de renovar na sociedade brasileira o debate de importantes aspectos relacionados aos fundamentos, estratégias e à própria eficácia dos instrumentos de Política Social aplicados às questões da fome e da pobreza. Neste debate, esteve presente, num quadro mesclado de preocupação simultânea com assistencialismo e impacto, a questão do controle do uso do auxílio financeiro, ou seja, o repasse direto a um membro de cada uma das famílias que deverá usufruir dos alimentos a serem adquiridos no comércio.

Por ocasião da divulgação do primeiro desenho do Programa, ocorrido ainda no período de transição de governo, a Secretaria de Estado de Assistência Social (SEASS) divulgou dados sobre a operação da sua Rede de Proteção Social - justamente baseada em transferências monetárias realizadas diretamente a famílias pobres, sob várias modalidades programáticas -, assegurando 0 sucesso gerencial do cartão magnético bancário entregue a cada família. Criticando especialmente, como "retrocesso", o fornecimento de cupons para uma alimentação dirigida - que ignorava esse mecanismo do cartão já pronto e testado -, a então titular da pasta levantou a necessidade de ultrapassar o preconceito de "que pobre não sabe gastar dinheiro e que vai comprar cachaça". "Além disso", acrescentou, "a gente vem descobrindo que existe uma racionalidade no uso desse recurso, racionalidade maior se você coloca esse recurso na mão da mulher". ${ }^{1}$

Esta avaliação positiva da participação da família em programas assistenciais parece fazer parte de uma tendência mais geral em termos da organização atual do conjunto do sistema de proteção social do país e é indício de que vem sendo reconhecida cada vez mais a importância da mulher na estrutura interna do grupo familiar doméstico e na administração da própria sobrevivência grupai.

\section{O lugar da família nos sistemas de proteção social}

Nos anos recentes, especialmente a partir da década de 90, o grau de expectativas colocadas sobre a família dentro do Estado de Bem-Estar Social tem com razão adquirido grande centralidade no debate sobre os resultados dos diversos modelos vigentes. A questão

\footnotetext{
Secretária Wanda Engel, entrevista ao jornal Folha de São Paulo, 30 out. 2002, p. A11.
} 
se prende basicamente ao equilíbrio entre as pressões colocadas sobre ela e os meios socialmente proporcionados para seu desempenho, enquanto instância interveniente, atuando em conjunto cm o Estado de Bem-Estar Social, no processo de reprodução social.

No Brasil, a comprovação da importância da participação da família e da mulher na operação de programas sociais, conforme aparece atualmente pela difusão nacional de projetos de combate à pobreza com transferência monetária direta, ainda que sugestiva, não é fato novo. Programas de provisão de moradia, por exemplo, vêm optando entre nós, há décadas, por colocar o documento de propriedade do imóvel no nome da mãe, figura cuja maior permanência ao lado dos filhos enseja o uso mais continuado do abrigo pelo grupo.

Atradição parece bem anterior, segundo Marshall. Remonta a recomendações relativas à aplicação da Lei dos Pobres na Inglaterra e em outros países, como depreendemos das orientações no caso inglês, que chamam basicamente a atenção para "se tratar a família como uma unidade, quando se trata de agir em relação à miséria", pois nela estão presentes os vários fatores causais da situação. Este procedimento, diz o autor, tanto serve para fins de cálculo do auxílio financeiro baseado na consideração dos recursos familiares princípio consagrado desde a era elisabetana - quanto na maior eficácia da abordagem dos problemas individuais mediante apelo aos recursos do ambiente familiar, conforme consagrado nas técnicas do serviço social de casos. ${ }^{2}$ Instruções de 1912 estabelecem que o total do auxílio a ser concedido a uma família com crianças devia ser medido pelo "padrão de renda normal com a qual se pode esperar que uma mulher eduque sua família". Posteriormente, o plano hospitalar do Governo critica ainda a ausência da figura do "médico de família", especialmente considerando a necessidade de evitar internações desnecessárias. Na discussão parlamentar prolongada sobre o destino da Lei dos Pobres, a oposição à ênfase na assistência prevista para a unidade familiar contrapunha, ainda segundo Marshall, que "cada membro de uma dessas famílias exige, para recuperação, um tratamento especializado de acordo com a necessidade dele ou dela", prenunciando a discussão contemporânea relativa à tensão entre cuidados familiares e atenção ao indivíduo, enquanto política de benefícios sociais (Marshall, 1967, p. 53-56, p. 186).

${ }^{2}$ O procedimento tem definido como seu lado bom o fato de que o trabalho de assistência social é mais eficaz se baseado na unidade familiar, diz Marshal (1967). 
As observações feitas, a partir de Marshall, evidenciam que à família sempre foi dado um lugar no âmbito dos sistemas de proteção social, porém a construção desse lugar se diferencia no contexto desses diferentes sistemas e comporta vários caminhos analíticos.

Dentre estes caminhos, podem ser arrolados: a família do provedor masculino, o "familismo", a família nos sistemas de proteção social de orientação social-democrática.

\section{A família do provedor masculino}

A perspectiva clássica, comum à maior parte dos Estados de Bem-Estar Social, é relativa à instituição do beneficio do seguro social público com fundamento na família do trabalhador, ou seja, concedido diretamente a ele enquanto provedor do grupo familiar. Sua inspiração é claramente a de um período de oferta de empregos estáveis, capazes de proporcionar salários familiares e de repetir-se para as novas gerações. Aposta-se, portanto, na existência de fortes laços intra-grupo familiar, de empregos disponíveis e renováveis, dirigindose para a concentração na cobertura dos riscos comuns à força de trabalho empregada - acidentes de trabalho, doença, velhice e invalidez, desemprego. ${ }^{3}$

Esta opção supõe, evidentemente que se desenvolvam internamente à família elevadas transferências materiais e imateriais. Ou seja, baseia-se na existência de uma solidariedade familiar que implica trocas intergeracionais e de gênero, constantes e fundamentais para a sobrevivência de todos.

Nesta direção, pode-se afirmar que a responsabilidade familiar é tradicional e marcante na cobertura dos riscos do "curso de vida", pelo contrato intergeracional em que os jovens adultos cuidam dos idosos que lhes transferiram patrimônio (Esping-Andersen, 1999, p. 41). Ela é particularmente necessária diante da evidência de uma concentração da pobreza na infância e na velhice, dada a relação desproporcional entre ganhos e necessidades específicas das famílias na primeira e última fase de seu ciclo vital, conforme explicitado no começo do século XX na formulação de Rowntree a

$3 \mathrm{Na}$ implantação do seguro social obrigatório, a cobertura dos riscos é gradativamente assumida, com precedência, em grande parte dos países, do seguro para acidentes de trabalho, na medida dos danos crescentes que acarretava e da maior facilidade de reconhecimento de um interesse partilhado entre patrões e empregados. A adoção do seguro-desemprego vem em geral por último, pedindo maior ruptura com a tradição liberal de considerá-lo risco individual. Cf. Ferrera (1984, p. 22-23). 
respeito do "ciclo de pobreza da vida da classe trabalhadora" (Rowntree, 1901, apud Esping-Andersen, 999, p. 41)

Nesta medida, o grupo familiar aparece com dupla face, a de uma unidade econômica com dependentes e "chefes de família" que redistribuem renda e a de unidade "doadora de cuidados", também a partir de redistribuição interna. Nele, da mulher-mãe se espera que seja a principal provedora de cuidados para os seus membros, mantendo-se economicamente dependente de seu marido. Assim supõe-se, por um lado, as responsabilidades do "chefe de família" com o sustento, e por outro, as da mulher com o cuidado. Esta expectativa atribuída ao grupo familiar quanto à proteção social autoriza uma constatação clara, conforme expresso para a Itália: "a família, com sua divisão de responsabilidade e de trabalho, de acordo com o gênero e as gerações, e com sua estrutura assimétrica de interdependências é o parceiro explícito do Welfare State" (Balbo, 1977,1984, apud Saraceno, 1994, p. 61, trad. nossa).

Como em todas as sociedades baseadas na união trabalhodireitos, é o primeiro que permite o acesso ao sistema de seguro social, à moradia subsidiada ou pública, ao crédito a juros mais baixos, entre outros benefícios. Dessa forma, aos filhos e à esposa é garantido acesso subordinado aos direitos sociais, enquanto mantêm uma relação familiar com uma pessoa que possui o "status" de trabalhador; poder-se-ia chamá-los "direitos derivados". Sendo, em geral, o seguro social - como benefício de "primeira classe" -, prioritariamente dirigido aos homens -, às mulheres restam os benefícios da assistência social, aqueles "de segunda classe" (Lewis, 1997, p. 331-339). Ainda considerando esta condição feminina, foi cunhada a expressão "o proletariado do proletariado". A idéia de "desmercantilização" do custo da reprodução social, conforme suposto na básica classificação dos "Três Mundos do Bem-Estar Social" no capitalismo 4 proposta por Esping-Andersen (1990), seria assim baseada num desvio do tratamento de gênero.

Sem concordar com a invalidação de sua tipologia do Estado de Bem-Estar Social em benefício de outra, definida a partir de um eixo na relação entre géneros, o autor reconhece que a família, embora anunciada por ele como instância de produção de bem-estar social, foi "dolorosamente" abandonada na análise central. Esta última

${ }^{4}$ Cf. Esping-Andersen (1990). O autor utilizou centralmente este conceito, segundo ele sugerido originalmente por Polanyi (1944) e posteriormente desenvolvido por Offe (1972, 1984). Cf. Esping-Andersen (1999, p. 43). Cf. Campos (1998, 1999) para comentário acerca dessa aplicação. 
acabou privilegiando a definição das posições de Estado e mercado (Esping-Andersen, 1999, p. 47), uma preocupação que, aliás, a nosso ver, tem ocupado recorrente e exageradamente o estudo atual das tendências da política social. Ele admite que realmente os sistemas de proteção social, onde os benefícios são derivados de emprego ou carreira, favorecem implicitamente o provedor do sexo masculino, já que a mulher tem, em geral, laços mais frágeis com o emprego. Quando o casamento se torna instável, ou em famílias de mães apenas, "o acesso da mulher à proteção social é prejudicado" (Gornic, 1997, apud Esping-Andersen, 1999, p. 50, trad. nossa).

Para o que nos interessa aqui, é importante reter o grau de "naturalização" das obrigações familiares. As questões de dependência e interdependência que criam responsabilidades familiares diferenciadas dos indivíduos pertencentes ao grupo são dadas como óbvias. Está implícita a operação da solidariedade da família, indispensável à manutenção do próprio grupo, de forma que a tendência é de não reconhecimento, da parte do Estado e da sociedade, dos limites econômicos e sociais dessa contribuição. Isto leva frequentemente à presença de uma política familiar muito passiva e não desenvolvida, o que pode parecer paradoxal quando se pretenderia reforçar o desempenho da família. ${ }^{5}$

\section{O" familismo"}

O "familismo", na expressão empregada por vários autores (em especial Esping-Andersen, 1999, p. 45; Saraceno, 1994, p. 60-81), deve ser entendido como uma alternativa em que a política pública considera - na verdade exige - que as unidades familiares assumam a responsabilidade principal pelo bem-estar social. Justamente porque não provê suficiente ajuda à família, um sistema com maior grau de "familismo" não deve ser confundido com aquele que é prófamília.

Dentro desta perspectiva, é fecundo analisar a condição da família no conjunto do sistema de proteção social da Europa Continental, evitando uma indevida generalização. Estes países, independentemente de terem progredido em graus variados na direção da seguridade social, são justamente aqueles que têm originalmente seus sistemas de bem-estar social repousando

5 O fato mereceu justamente uma arguta expressão de Saraceno: "familismo ambivalente". Cf. Saraceno (1994, p. 60-81). 
largamente sobre um desenvolvido seguro social obrigatório. Configura-se, assim, a situação relativa a benefícios indiretamente concedidos aos membros da família, a partir da já discutida concessão feita ao trabalhador "chefe da família". Compartilhando essa condição básica, divergem, entretanto, por razões de seu desenvolvimento histórico, quanto à implementação de uma política familiar.

Na França, por exemplo, a forte consciência do risco quanto à própria reposição demográfica, causada pela queda vertiginosa da natalidade no final do século XIX, levou à formação de um consenso nacional sobre a necessidade de uma política estatal sistemática de fortalecimento da família (Lenoir, 1991, p. 149). A política da família foi defendida, por um lado, em grande parte pelo "catolicismo social", com objetivos conservadores na restauração de ideais morais e no respeito à liberdade de escolha da família. Por outro, simultaneamente, pelo apoio dos setores portadores de uma visão laica e republicana defensora de direitos, tais como: do divórcio (reconhecimento da natureza contratual do casamento), dos filhos naturais, de maior autonomia das mulheres (Battagliola, 2000, p. 146). Comportando posições diferenciadas, a tensão ingerência/não intervenção na família foi contornada especialmente pelo avanço dos cuidados da proteção à infância, procedimento que se apresentava com maior facilidade de aceitação política, e também reconhecido como muito necessário. São evidentes visões concorrentes sobre a família.

Ao longo da história do século XX, a política familiar caminhou para uma posição de menor independência, tendendo a figurar como instrumento da política mais global. A atenção à família na agenda política francesa, entretanto, sempre se manteve.

No governo Mitterrand, as mudanças em termos programáticos e administrativos não parecem ter sido substanciais, incluindo mudanças no valor e tipo das alocações, facilitação da adoção. Uma agenda pendendo para o favorecimento da criança em lugar da família. Também foi o momento do reconhecimento social e plenamente legal das mudanças na conjugalidade. Uma revivência do natalismo na instituição de um subsídio financeiro para qualquer pessoa interessada em parar de trabalhar ou reduzir horas de serviço por ocasião do nascimento de uma criança, além das duas primeiras, aparece (Lenoir, 1991, p. 179).

Esta situação francesa configura uma outra condição da família dentro do sistema de proteção social: são-lhe conferidas 
responsabilidades de apoio e sustento de seus componentes, mas a ela se destina, paralelamente, substancial auxílio monetário e/ou de serviços, formulado e entregue com base na específica caracterização da unidade familiar.

A distinção é muito significativa em relação ao sistema de proteção social italiano, ao qual se pode atribuir um alto grau de "familismo".

No caso da Itália, aponta-se uma situação contrária, a de não existir uma política articulada para a família, devendo esta ser pesquisada e reconstruída no interior da legislação social e fiscal e da política social em geral, frequentemente implicando em contradição de objetivos ê fragmentação da implementação (Saraceno, 1998, p. 7). Sem depreciar a existência de múltiplos dispositivos legais e de políticas públicas relacionados à família, e sua força normatizadora, estamos longe de uma política familiar consistente. As medidas direcionadas às famílias são mais efeitos de outras políticas setoriais, ou gerais, como é o caso das pensões, da educação e da saúde. Esta insuficiência se espelha na ausência de benefícios que reforcem especificamente os "cuidadores" da família diante das responsabilidades a ela atribuídas. À mulher são oferecidos poucos direitos, além de licenças no emprego, alguma oferta de serviços (Saraceno, 1998, p.12) e, mais recentemente, a aposentadoria para "donas de casa".

Ainda outros fatores históricos importantes podem ser adicionados para compreensão dos diferenciais entre os países. É o caso daqueles que até um passado relativamente recente contaram com ditaduras e totalitarismo. Na Alemanha, por exemplo, as restrições a uma política familiar que fosse claramente assumida pelo sistema alemão oriental nos tempos pós-nazistas, se fundamentam na permanência de sua identificação com os objetivos natalistas e de reforço da política de Hitler (Schulteis, 1996, p. 209210).

A mesma situação é apontada para a Itália, com referência às várias formas de encorajamento à natalidade do regime fascista, encontrando-se, entre os fatores responsáveis pelo retardamento de uma política para a família, a fuga à tradição fascista de política familiar, com objetivos claros de apoio aos valores do regime, reforço da autoridade e reversão da tendência à baixa da fecundidade (Saraceno, 1998, p. 11). Também no caso espanhol, a necessidade de "rejeitar a herança de um passado autoritário", da política familiar 
franquista, natalista e anti-feminista, deixou até hoje marcas no desenvolvimento dessa política. Mesmo após 1975, ela sofre oposição de vários setores, assim sem renovação profunda da orientação anterior (Valiente, 1997, p. 393-399).

Para uma visão de conjunto das medidas especialmente propostas e desenvolvidas para famílias, o retrato da União Européia nos mostra que, de maneira geral, as "alocações familiares" são elementos centrais no quadro das prestações diretas às famílias, ao lado da operação através do sistema fiscal. Em oito países da União Européia, estas prestações têm um caráter universal, aberto a todas as famílias, sem exigências contributivas anteriores. Nos países do Sul da Europa, as prestações familiares são relativamente muito menos elevadas que nos outros Estados membros da União ${ }^{6}$ (Eurostat, 1995).

A polarização entre universalismo de cobertura a todos os cidadãos, e benefícios para grupos específicos, acompanha a história da atenção à família nos diferentes sistemas. Na Itália, o apoio promovido por grupos e movimentos nas décadas de 70 e 90, para a expansão de serviços com base no atendimento aos direitos individuais enquanto forma de aliviar os encargos e a dependência familiar, foram interpretados como um desvio individualista, uma distorção que "teria contribuído para o enfraquecimento da unidade e da solidariedade da família e mesmo de seus deveres, representando uma intrusão indevida do Estado no modo de regulação da família" (Saraceno, 1998, p. 12, trad. nossa). Na França, o debate sobre o rompimento do universalismo republicano, com medidas voltadas ao segmento de famílias mais numerosas, aparece, até recentemente, na oposição ao salário maternidade do governo Mitterrand (Lenoir, 1991). Para o caso francês, dada a preocupação mais com as crianças do que com a mulheres, ainda que considerando estas em sua condição de mães e trabalhadoras, podese falar no desenvolvimento de um "modelo parental" (Lewis, 1992, apud Martin, 1997, p. 344).

\section{A família na via social-democrática do Estado de Bem-Estar Social}

Para estabelecer a diferença essencial deste caso em relação aos anteriores, devemos falar aqui no objetivo do Estado de procurar

${ }^{6}$ O texto trabalha com os 12 países então membros da União Europeia. 
socializar antecipadamente os custos enfrentados pela família, sem esperar que a sua capacidade se esgote. Isto se materializa em transferências ao indivíduo - e não à família -, diretamente aos filhos e no provimento específico e independente de serviços para o cuidado de crianças, idosos e deficientes (Esping-Andersen, 1999, p. 51,61).

A oferta de serviços sociais de apoio aos encargos familiares constitui alternativa clara, favorecendo uma política de liberação do trabalho feminino para o mercado. São eles amplamente desenvolvidos na direção de uma cobertura universal da população. Dessa forma tornam-se, simultaneamente, um importante fator na expansão de postos de trabalho, correspondendo ao objetivo macroeconômico de pleno emprego.

O autor afirma que essa diretriz só se corporificou na década de 60 , sob pressão de movimentos feministas, podendo ser considerada pioneira no conjunto dos países. Lembra que nem mesmo a proposta da seguridade social a contemplava, como se vê na afirmação de Lord Beveridge sobre a necessidade de termos a grande maioria das mulheres ocupada com trabalho não pago, sem a qual seus maridos não poderiam fazer o trabalho pago, vital para a nação (Beveridge, 1942, p. 49, apud Esping-Andersen, 1999, p. 45). Fornece os principais elementos do sistema esta caracterização:

os países escandinavos ultrapassaram a adoção do modelo do provedor masculino, comum à quase totalidade dos Estados de Bem-Estar Social, colocando as mulheres em empregos a partir dos anos 70, introduzindo a taxação de impostos e licenças do trabalho para cada um dos pais em separado e aumentando a provisão social de cuidados à criança, até o ponto em que a família com dois provedores se tornou a norma. (Lewis, 2000, p. 39, trad. nossa)

Exemplo da orientação vigente nos países compreendidos pelo modelo escandinavo é o disposto na legislação de países como a Suécia, onde os filhos foram isentos da responsabilidade de sustentar seus pais antes de 1956, da mesma forma que em 1964 na Noruega e em 1970 na Finlândia, ocorrendo de forma mais profunda esta tendência na Dinamarca, onde tal obrigação nunca constou em leis (Fargion, 2000, p. 64).

Esta autora constata que, mesmo não se podendo afirmar que estes países ficaram imunes à reorganização pós-crise relacionada ao ajuste fiscal, os dados mostram continuidade da provisão pública da maior parte dos serviços, permanecendo a cobertura das 
necessidades muito acima da existente em outros países europeus (Fargion, 2000, p. 84).

Pruzan (1995), na sua análise sobre política e família na Dinamarca afirma que a família dinamarquesa pode ser definida como família moderna à medida que comporta características como: o objetivo do casal é a relação entre os envolvidos, e não institucional; os elementos de união desse casal são vínculos emocionais e não de empenho e deveres entre eles; a unidade do casal é derivada de um acordo entre indivíduos autônomos e que provêm a si mesmos e não de uma instituição que satisfaz funções e regras sociais. Os papéis e deveres sociais dividem-se entre as duas pessoas, baseados no interesse e na competência e não no sexo. Dadas essas características, a família, em muitos aspectos, é uma unidade frágil onde o divórcio se apresenta como lógico e possível e convive com a presença maciça das mulheres no mercado de trabalho, em tempo parcial ou total.

Para a autora, o reconhecimento desse tipo de família exige uma abordagem muito pragmática por parte da sociedade, que se traduz no respeito aos modelos de convivência e à paridade de direitos e de oportunidades no âmbito da relação de casal. Isso exige o provimento de medidas de sustentação da estrutura familiar, que são contempladas principalmente através de um sistema público de escolas para crianças pequenas e da assistência pública para os idosos e portadores de deficiências, tornando possível a inserção estável das mulheres no mercado de trabalho. Relata a autora que as políticas familiares são entendidas como políticas (serviços e assistência) para virem atender às necessidades da família moderna, porém são direcionadas aos indivíduos.

\section{A posição da família na política social brasileira}

Como primeira abordagem de um tema que envolve questões altamente complexas, e sem tentar fazer um exame completo das mesmas, optamos por reunir neste momento alguns dos elementos legais e operacionais que marcam a posição da família no âmbito da política social brasileira - particularmente da assistência social - e que permitem a construção de uma primeira aproximação analítica.

A responsabilidade familiar no âmbito da reprodução social, como pudemos verificar, é tratada de diferentes formas no contexto das nações. Em muitas delas, como vimos em países da Europa do 
Sul, a família, mediante a divisão de tarefas e responsabilidades entre gênero e gerações, constitui instância fundamental para o Estado de Bem-Estar. Assim, não é um acaso a presença de um modelo de solidariedade familiar vigente. Não existe apenas porque praticado de fato pelas famílias: a solidariedade é obrigada por lei, conforme prevêem as legislações vigentes sobre a convivência familiar nos diversos países.

Certamente a definição, explícita ou implícita, da política pública relacionada à família, influencia o tamanho, composição, comportamentos, normas e valores familiares e paralelamente sua posição no contexto maior da sociedade. Neste processo, evidenciam-se as diferenças relativas à definição e à implementação das ações estatais.

O Brasil teve também uma forte orientação relativa ao direcionamento da família no sentido do estabelecimento de padrões ligados a seu papel na reprodução social, entendidas aí diretrizes quanto aos cuidados com a maternidade, educação e criação dos filhos, o trabalho feminino e a sua contribuição geral à ordem moral e social. Esta a inspiração do Estatuto da Família de 1939. Assumese uma verdadeira política, com proposição de regras para o casamento, incentivos financeiros, subsídios para aquisição da casa própria e outros.

Hoje, a responsabilidade familiar está espelhada na própria Constituição.

Em seu Capítulo VII, versando especificamente sobre a família, a criança, o adolescente e o idoso, atribui aos filhos a obrigação de cuidar dos pais quando estes chegarem à velhice, em situação de carência ou doença, bem como estabelece a responsabilidade dos pais na criação dos filhos (Artigo 229). Logo em seguida, o Artigo 230 define que o cuidado com os idosos é dever conjunto da família, do poder público e da sociedade, "assegurando sua participação na comunidade, defendendo sua dignidade e bem-estar e garantindoIhes o direito à vida". No parágrafo primeiro, afirma-se a preferência de programas para os idosos feitos em suas casas, evitando a institucionalização.

Ainda na Constituição, é possível encontrar diversas outras disposições quanto ao tratamento dos idosos, como é o caso da assistência social obrigatória (art. 201, I e 203,1); da desobrigação de alistamento eleitoral e do voto para maiores de 70 anos (art. 14, 
$\S 1^{\circ}, \mathrm{II}, \mathrm{b}$ ); do transporte gratuito para maiores de 65 anos (art. 230, $\left.\S 2^{\circ}\right)$.

Quanto à assistência social, a Constituição de 1988 estabeleceu-a como benefício não contributivo, fornecido "a quem dela necessitar". Em sua Seção IV - Da Assistência Social - Artigo 203, Inciso V, determina "a garantia de um salário mínimo de benefício mensal à pessoa portadora de deficiência e ao idoso que comprovem não possuir meios de prover a própria manutenção ou de tê-la provida por sua família, conforme dispuser a Lei" (grifo nosso).

Na legislação ordinária, merecem referência destacada alguns casos:

a) A Lei 8.842, de janeiro de 1994, que dispõe sobre a Política Nacional do Idoso (PNI), estabelecendo que os maiores de 60 anos serão objeto de atenção especial do Estado.

Afirma, entre suas nove diretrizes básicas, a prioridade para a família enquanto instituição mais capaz de produzir o bem-estar do idoso, já que a internação em asilos ou hospitais só deve ocorrer como última alternativa. Esta diretriz está de acordo com outras, relativas à importância da "integração social" do idoso à sociedade, sua convivência com várias gerações e participação em associações, evitando o isolamento.

b) O Estatuto da Criança e do Adolescente (ECA) - Lei 8.069, de 13 de julho de 1990 - vazada na doutrina da proteção integral, que veio transformar bastante os fundamentos da atenção à criança e ao adolescente no País, após inédita e significativa aproximação, e pressão, de vários setores da sociedade junto aos constituintes de 1988. Os Artigos 19, 22 e 23 do ECA, tomados conjuntamente, permitem uma boa compreensão da grande prioridade dada, no texto legal, ao direito à convivência.familiar e comunitária. No Artigo 19, afirma-se o direito a ser criado e educado na própria família, ou, na impossibilidade desta, numa substituta. No 23, dispõe-se sobre a proibição de uso da carência de meios materiais da família para suspensão do pátrio poder, corrigindo situação anterior de prática comum desta punição, que facilitava a institucionalização do adolescente em conflito com a lei. Quando tal carência ocorrer, para permitir a permanência da criança na família, esta "deverá obrigatoriamente ser incluída em programas oficiais de auxílio". O artigo 22 define: "Aos pais incumbe o dever de sustento, guarda e educação dos filhos". 
É visível no ECA a especificação de grande número de direitos das crianças e dos adolescentes, presentes expressamente no Artigo $4^{\circ}$. O mesmo artigo atribui o dever de efetivação desses direitos à família, à comunidade, à sociedade em geral e ao Poder Público. Conquanto se trate aqui de uma responsabilidade compartilhada, a posição da família é reforçada no conjunto da lei. Nesse sentido pode-se observar o grande impulso dado às ações assistenciais e ao controle público, implementados pela sociedade civil. Não foi, entretanto, substancialmente preenchido o vácuo da ação estatal, ao cumprir-se a exigência do abandono da anterior política de privação de liberdade.

c) A Lei Orgânica da Assistência Social (LOAS) - Lei 8.742, de 7 de dezembro de 1993 - em seu Artigo $2^{9}$, inciso V, estabelece a regulamentação do benefício assistencial, o Benefício de Prestação Continuada (BPC), garantindo um salário mínimo de benefício mensal à pessoa portadora de deficiência e ao idoso que comprovem não possuir meios de prover a própria manutenção, ou de tê-la provida por sua família. Este direito é hoje reconhecido a todas as pessoas idosas, com 67 anos ou mais. Tal direito concerne também a todas as pessoas portadoras de deficiência, incapacitadas para a vida independente e para o trabalho, de qualquer idade. Em ambos os casos, as pessoas devem ser pertencentes a famílias com renda mensal familiar per capita inferior $a^{1}{ }_{14}$ do salário mínimo, e recebem o auxílio, independentemente de terem realizado contribuições para a Previdência Social

A lei afirma a assistência social enquanto "direito do cidadão e dever do Estado ... Política de Seguridade Social não contributiva, que provê os mínimos sociais, realizada através de um conjunto integrado de ações de iniciativa pública e da sociedade, para garantir 0 atendimento das necessidades básicas" (art. $1^{\circ} \mathrm{e}$ inciso IV do art. $4^{\circ}$ da Lei). A lei coloca a exigência de revisão dos benefícios concedidos, a cada dois anos, "para verificação da continuidade das condições que lhe deram origem" (art. 21).

Estas características da lei têm impactos sobre o tratamento dos direitos da família, considerando-se o valor relativamente baixo do benefício, apesar dos esforços desenvolvidos para mudança legal (Ferreira, 1999, p. 70). A adoção do salário mínimo como renda capaz de fazer face à provisão de necessidades de uma família de quatro pessoas (só abaixo do qual cabe o BPC) leva a um cálculo previsto 
na lei que deixa implícita a possibilidade de uma pessoa poder manter-se recebendo menos que um salário mínimo, quer dizer, com uma quarta parte dele. Em segundo lugar, pode-se inferir que o fato de pertencer a uma família potencializa o uso dos recursos, pela coabitação e outras trocas, permitindo manter um per capita de sobrevivência, e portanto de concessão do benefício, bastante baixo. Este procedimento, por parte da Seguridade Social, tem dado mesmo margem a interpelações legais.

A possibilidade de revisão - tanto médico-pericial como social -evidencia a dependência da concessão do benefício à comprovação da impossibilidade de sustentar-se por conta própria, com cancelamento, se a renda familiar melhorar.

Questão mais central nessa discussão tem sido a própria definição da família enquanto critério para alocação do recurso financeiro. Conceituou-se inicialmente a família, para efeito do cálculo da renda familiar per capita mensal, com base no definido no Artigo 20, parágrafo $1^{\circ}$ da LOAS, como sendo "a unidade mononuclear, vivendo sob o mesmo teto, cuja economia é mantida pela contribuição de seus integrantes". Nesse momento, não estava presente o critério de consanguinidade na definição de família, incluindo-se nela outras pessoas agregadas. Este conceito de família foi alterado (Medida Provisória 1.473-34, de 8 de agosto de 1997, transformada na Lei 9.720, em 30 de novembro de 1998), passando a considerar o "conjunto de pessoas elencadas no art. 16 da Lei 8.213, de 24 de julho de 1991, desde que vivam sob o mesmo teto". Atende-se assim o cônjuge, o companheiro(a), os pais, os filhos e irmãos e os equiparados a essas condições, não emancipados, menores de 21 anos ou inválidos. Adotou-se a concepção da família previdenciária. A inclusão de determinados membros no conjunto da família, ou, ao contrário, algumas exclusões, têm a tendência a alterar significativamente a média salarial per capita- tanto por fazer variar o montante das rendas como o do número de pessoas incluídas para o cálculo -, determinando se um indivíduo tem direito, ou não, ao benefício.

Enfim, fica demonstrado claramente nos dispositivos legais e na operação dos programas assistenciais, a dependência do reconhecimento do direito individual às condições da família, consagrando o princípio da responsabilidade subsidiária do Estado quanto a ela. 
Ainda cabe comentar que, apesar de disposição da LOAS, que, no tocante aos procedimentos de consubstanciação da política de Assistência Social, destaca a importância do desenvolvimento conjunto de serviços, programas, projetos e benefícios, observa-se na prática que as transferências monetárias têm constituído a maior parte, para não dizer a única, via de sua implementação. A escassa oferta de programas e serviços aparece como um grande limite no contexto da implementação dos programas de transferência de renda no Brasil. É um fator determinante para o agravamento da falta de articulação da política compensatória com as políticas estruturantes. Esta articulação, entre outras consequências, abriria a "perspectiva de rompimento com a admissão da família como unidade básica para atendimento" (Silva, 2002, p. 373).

Segundo Boschetti (2002), o isolamento da política de assistência social, com seus fortes traços de residualidade, seletividade e focalização como bases de sua efetivação, fortalece 0 viés assistencialista em detrimento da perspectiva de acesso aos direitos sociais. Quer dizer que a assistência social na "era das bolsas" é marcada por um caráter marcadamente curativo, tendo perdido força os projetos de caráter mais preventivo. Para a autora, os Projetos de Enfrentamento à Pobreza, para geração de emprego e de renda - com seus recursos diminuídos e sem menção nos relatórios de 2000 e 2001 da Secretaria de Estado de Assistência Social (SEAS) e nos demonstrativos de execução do Fundo Nacional de Assistência Social (FNAS) - tendem a ser desativados.

Assim, devemos reconhecer hoje o uso extenso de programas de manutenção de renda não universais, que funcionam de forma descontínua (em termos operacionais, prolongados atrasos de pagamento, por exemplo, são comuns), propiciando em geral auxilios bastante difusos e modestos e centrados em trabalho com famílias.

Além das leis arroladas, merece consideração a legislação sobre a Renda Mínima. Sobre ela, é importante ressaltar que as discussões havidas entre a primeira tentativa de estabelecer a obrigação legal de concessão de uma Renda Mínima no país-projeto inicial de lei apresentado pelo senador Suplicy, e aprovado por unanimidade no Senado em 1991 - até a promulgação da lei de 1997, atualmente em vigência, oferecem talvez uma das melhores 
oportunidades para visualizarmos a progressiva importância da consideração da família como instância de alocação de recursos.

Em termos breves, o projeto de 1991 estabelece o direito individual à renda, administrado em nível federal, definindo o montante concedido a partir da posição diferenciada de cada cidadão em relação a um patamar de renda considerado mínimo. Ao contrário, o dispositivo de 1997 autoriza a União a desenvolver projetos associados com municipalidades, considerando a existência nestas de níveis abaixo da média, em termos de arrecadação e de renda familiar. Estes obedecem à legislação específica dos municípios e apresentam-se condicionados à disponibilidade orçamentária (Fonseca, 2001; Silva, 2002).

Do ponto de vista da vinculação dos critérios de concessão do benefício à família, que nos interessa prioritariamente aqui, um recorte importante foi estabelecido ao acoplar-se os programas de renda mínima à educação dos filhos. Este procedimento se insere na proposta maior de associação da transferência monetária às famílias à interrupção da repetição da pobreza intergeracional, especialmente pelo aumento do capital educacional. É geral a relação dos programas atuais de renda mínima de iniciativa estadual e especialmente municipal, desde os pioneiros iniciados a partir de 1995, com a educação dos filhos. São direcionados a famílias que possuem crianças em idade escolar, sendo este um dos critérios de elegibilidade para acesso aos programas.

\section{Família e política de assistência social brasileira: uma aproximação analítica}

Tomando como parâmetro os diferentes lugares que a família ocupa nos sistemas de proteção social e relacionando-os à situação brasileira, tanto em termos dos dispositivos legais como operacionais a ela dirigidos dentro do nosso sistema de proteção social especialmente na política de assistência social - é possível afirmar que no país temos uma orientação eminentemente "familista".

Deve-se reconhecer que esta não é uma característica nova, mas incrementada vertiginosamente desde a última década do século passado. Este incremento vem se fazendo através de um discurso de recuperação de valores ético-morais, que estariam supostamente perdidos na sociedade, e em prol da convivência familiar e 
comunitária. Parte da lógica político-econômica pautada nas agências internacionais, e há expectativa de que a família exerça um papel decisivo, até substitutivo, em relação ao acesso, cada vez mais incerto, ao sistema de direitos sociais (Mioto, 2000; Bianco, 1995).

As informações que as pesquisas da área demográfica nos trazem e pelo conhecimento científico acumulado, temos claras indicações da diminuição da "capacidade protetora das famílias", de camadas populares e também de segmentos médios, estando as mesmas, portanto, impossibilitadas de atender a tamanhas expectativas. A diminuição de sua "capacidade protetora" está vinculada ao empobrecimento acelerado da população brasileira nas décadas pós-ajuste estrutural, aliado às configurações renovadas da família brasileira. As transformações ocorridas na família, desde a metade do século passado, embora tenham um saldo altamente positivo relacionado à possibilidade de maior convivência entre as gerações, mudanças na relação homem/mulher, mudanças no caráter do vínculo do casamento, fizeram com que a família também se tornasse muito mais vulnerável no contexto social (Barg, 2003). Por exemplo, famílias menores são muito mais sensíveis às situações de crises, mortes, desemprego.

Do ponto de vista do tratamento dado à família na análise de sua contribuição em programas sociais, durante muito tempo centrada na sua capacidade de criar e conduzir "estratégias de sobrevivência" que potencializam as oportunidades de vida, cabe uma avaliação no momento em que há mudanças adversas na situação de emprego e renda.

Esta preocupação, especialmente envolvida com "a erosão do trabalho e o crescimento do informal", tem motivado pesquisas, œmo a de Rocha (1997, 2001), para estudo de casos de vários países e de um estudo qualitativo conduzido no México, aportando elementos de comparação na América Latina. Comentando a ênfase de vários estudos sobre esta "habilidade" de adaptação das famílias, mediante seus esforços, adverte que a premissa obscurece tanto o fato de que pode haver limites para este comportamento adaptativo das pessoas pobres como o grau de impacto das crises económicas sobre os vários membros da família, levando em consideração idade e género. Constata, também, que, sob pressões da pobreza, tem havido uma decadência das trocas sociais e das chamadas "redes", "capital social" sobre o qual se baseia grande parte da estratégia familiar de sobrevivência. Em circunstanciada análise, arrola várias 
formas - diríamos "estratégicas" ? - usadas pelo grupo familiar nos diferentes países: aumento do tempo de trabalho dos membros adultos; incorporação das crianças ao trabalho e sua retirada da escola; apelo a atividades ilegais como fonte de renda; redução e mudanças do consumo alimentar; venda de objetos de valor do patrimônio familiar ou gastos da poupança; aumento da produção para consumo próprio; redução de vários itens de consumo, como vestuário, transporte, despesas médicas, entre outras.

Consideração conclusiva da autora é de que hoje deveríamos mais falar num modelo da "pobreza de recursos" das famílias em lugar do anterior "recursos da pobreza" (Rocha, 1997).

Com relação às redes de solidariedade, merece atenção, também, pesquisa nacional conduzida em Portugal que, entre muitos outros elementos, as considera como rareando na medida em que nos aproximamos da base social, nos estratos de menos recursos. Chama a atenção para o fato de aqueles que estão no topo da pirâmide da renda fazem muitas e elevadas transferências, como especialmente no momento da união de um novo casal (Vasconcelos, 2002).

Um grande mérito desta investigação é trabalhar com a "família parentesco" - permitindo análise dos múltiplos e fundamentais aspectos da transmissão familiar -, sem o recorte - prático, mas reducionista - do grupo familiar doméstico, objeto adotado pelas estatísticas nacionais e por outras fontes de dados.

Dessa forma, a família se encontra muito mais na posição de um sujeito ameaçado do que de instituição provedora esperada. E considerando a sua diversidade, tanto em termos de classes sociais como de diferenças entre os membros que a compõem e de suas relações, o que temos é uma instância sobrecarregada, fragilizada e que se enfraquece ainda mais quando lhe atribuímos tarefas maiores que a sua capacidade de realizá-las.

Portanto, a pergunta que se coloca é: por que continuamos a operar, no âmbito da política social, com uma concepção alheia à realidade? Onde se ancora o forte caráter familista da política social brasileira e, particularmente, da política de assistência social?

A tradição "familista" no âmbito da política social tem se construído a partir do pressuposto de que existem dois canais "naturais" para satisfação das necessidades dos cidadãos: o mercado (via trabalho) e a família. Somente quando falham estes canais é 
que o Estado intervém, e de forma temporária. A partir dessa concepção se instaurou uma cultura prevalentemente assistencialista, que não conseguiu ser rompida, em muitos países, nem com o advento do Welfare State, como é o caso da Itália (Sgritta, 1988). Assim, no pensamento do autor, instauram-se as repúblicas fundadas na família, tendo questões como a maternidade e a infância privatizadas cada vez mais. Privatizadas no sentido de que problemas dessa natureza pertencem apenas à esfera do privado. Esta concepção está vinculada à ideologia secular onde a família é uma sociedade natural e sujeito econômico de mercado. A ajuda pública deve acontecer sob forma de compensação, por falimento ou pobreza, que, dentro de uma política de bem-estar, está ideologicamente traduzida como a garantia de um mínimo universal pelo Estado (Donati, 1996).

Acontece que, na maioria dos casos, como o brasileiro, o mínimo nem é universal, dada a seletividade do acesso, estando longe de orientar-se para atender às necessidades básicas. ${ }^{7}$ Esta concepção de que as famílias, independentemente de suas condições objetivas de vida e das próprias vicissitudes da convivência familiar, devem ser capazes de proteger e de cuidar de seus membros, está profundamente arraigada no âmbito da sociedade e tem certamente desdobramentos importantes na operacionalização de uma política de assistência social. Ela alimenta o estabelecimento de uma distinção básica entre famílias capazes e famílias incapazes, mais capazes ou menos incapazes ${ }^{8}$ (Mioto, 2000).

Como capazes são definidas aquelas que, via mercado, trabalho e organização interna - as famosas "estratégias de sobrevivência" - conseguem desempenhar com "êxito" as funções que lhes são atribuídas pela sociedade. Como incapazes são consideradas aquelas que, não conseguindo atender às expectativas sociais relacionadas ao desempenho das funções atribuídas, requerem a interferência externa, em princípio do Estado, para a proteção de seus membros. Ou seja, são merecedoras da ajuda pública as famílias que falharam na responsabilidade do cuidado e proteção de seus membros.

A categorização das famílias como capazes ou incapazes, sãs ou doentes, normais ou anormais, se encontra fortemente arraigada

Sobre a questão dos mínimos sociais, cf. Pereira (2000).

8 Esta divisão é apenas para efeito de exposição, pois na realidade não existem estas categorias em estado puro. Nenhuma família é totalmente autosuficiente, assim como não é totalmente dependente. 
no senso comum, assim como frequenta as propostas dos políticos e dos técnicos. A execução terminal dessa política pelos profissionais da área social, na maioria das vezes mergulhados nesta concepção tradicionalista, ou sem aportes teóricos para a discussão dos processos de inserção da família no âmbito da política social, coloca em movimento ações que produzem resultados justamente opostos, mesmo para aqueles potencialmente esperados na própria concepção dos programas sociais.

Assim nos parece estar sendo definido um processo de operacionalização da política de assistência social no Brasil, que se distancia tanto da perspectiva do direito, como do parâmetro das necessidades sociais. Nesta discussão, devemos atentar para o caráter privatista da implementação da política social brasileira, constitutivo estrutural, não podendo ser atribuído a um momento recente de hegemonia neoliberal. Especialmente dentro dela, a Assistência Social - onde é historicamente ainda mais exuberante a oferta privada - a partir da presença de organizações não lucrativas em associação com o Estado, este o principal financiador. Com o recente aprofundamento e aperfeiçoamento das relações de parceria, respaldadas em leis específicas da década de 90, acentua-se o aporte de recursos financeiros para projetos, com a gestão delegada à iniciativa privada. Dessa forma o Estado desloca, para o hoje chamado Terceiro Setor, grande parte da responsabilidade assistencial (Yasbek, 2002).

Tal situação tende a aumentar amplamente as possibilidades de manutenção da concepção "familista" e assistencialista que tem permeado a operacionalização da assistência social no Brasil, estabelecendo publicamente o lugar da família no âmbito do sistema de proteção social. Esta concepção não está apenas no bojo da construção da própria política mas perpassa todo o processo de intervenção pública na família.

Pereira (1995), ao discutir as respostas políticas relacionadas às questões da família no campo do bem-estar social no bojo da perspectiva pluralista, ${ }^{9}$ tão em pauta nos dias atuais, distingue duas concepções de pluralismo. Uma seria o pluralismo liberal centrado na idéia da transferência de responsabilidades do Estado para a sociedade civil, através do processo de descentralização calcado na

9 Para a autora, a perspectiva pluralista consiste na interação de diferentes iniciativas, sejam elas públicas ou privadas. Isto é, as iniciativas ou ações são realizadas de forma combinada entre Estado, Sociedade civil e Mercado. 
ótica da privatização. Esta concepção redunda em restrição ou destituição dos direitos sociais conquistados e prevê a aplicação do modelo residual de políticas públicas. A outra concepção, segundoa autora, seria o pluralismo coletivista. Esta prevê a participação da sociedade, porém não descarta a presença do Estado na provisão social. Trabalha com o modelo institucional de políticas públicas, assentado no princípio da universalidade e objetiva a manutenção e extensão de direitos. Estes, em sintonia com as demandas e necessidades particulares. Dessa forma não sobrecarrega a família, já que a política social provê suportes para ela.

Enfim, a contradição que marca a relação Estado-família, conforme já comentado para a situação da Itália e outros países, e que tem chamado cada dia mais a atenção dos interessados na temática da família, verifica-se no caso do Brasil: a despeito do que se observa na nossa legislação, na própria Constituição, onde a família aparece com destaque, gozando de especial proteção do Estado, ela vem sofrendo uma crescente queda da qualidade de vida, constatada atualmente pelos indicadores produzidos por várias fontes de pesquisa, estatais e/ou particulares.

Tal paradoxo se agiganta com a crise fiscal global, quando retoricamente setores das mais diferentes orientações políticas e ideológicas consagram constantemente a família como recurso fundamental para a construção da sociabilidade e da preservação do tecido social. Amplamente discutido hoje, tem sido reconhecido como presente na própria origem do Estado e da família burguesa. Não resolvido na maioria dos países, mesmo com a estruturação do Estado de Bem-Estar Social dentro do qual foi explicitado o reconhecimento da responsabilidade coletiva no enfrentamento das "dependências" individuais e familiares.

A expressão "neo-familiarismo" traduz o subjacente à tendência ideológica atual de transformar a unidade familiar em solução para a racionalidade do modelo global, reprivatizando atividades no passado tornadas públicas e trazendo a unidade doméstica - privada por definição - de volta para a sociedade em geral (De Martino, 2001, p. 111).

Em contrapartida, trata-se de incorporar realmente, nos sistemas de proteção social a concepção de que ninguém é totalmente auto-suficiente, e o bem-estar depende tanto de segurança em relação ao futuro e aos eventos críticos da vida, quanto da 
possibilidade de contar com uma rede de sustentação para garantir a reprodução cotidiana, social e biológica (Jelin, 1997).

Do ponto de vista que aqui nos interessa, é necessário refletir a articulação entre a ação de Estado, família e mercado, considerando-se especialmente estas mais que reconhecidas falhas do último para a administração dos "maus" riscos e o peso sobre a família que pode ser considerada "o destino último do consumo e alocação do bem-estar social" (Esping-Andersen, 1999, p. 36). Através do fio da análise dos riscos sociais a serem cobertos, consideramos a grande diferenciação de sua distribuição entre os vários segmentos populacionais e a consequente necessidade de escolhas de sistemas de proteção social orientados com mais eficácia na obtenção de maior igualdade de recursos para as pessoas no seu enfrentamento. A resposta supõe tanto a avaliação do tipo de riscos existentes como a viabilidade de criar "solidariedades sociais" suficientemente amplas para sua cobertura.

Neste processo, é interessante lembrar a distinção feita por Esping-Andersen entre "maus" e "bons" riscos. A absorção dos "maus" riscos, geralmente melhor localizados através de um corte de classe - mães sós, portadores de deficiências, por exemplo - recebe geralmente um tratamento residual a grupos específicos, em níveis financeiros baixos, com exigências de comprovação de necessidade e contrapartidas da parte dos beneficiários, para não correr o risco de sustentar desocupados. "O problema", ressalta o autor, é que os "maus" riscos são sempre aqueles que se apresentam mais desesperadamente necessitados (de resposta)" (Esping-Andersen, 1999, p. 39, trad. nossa). A crença de que a solidariedade familiar não falha na cobertura dos "maus" riscos pode ser vista como o fundamento escondido da atribuição das mais pesadas responsabilidades a ela.

Há sinais, entretanto, de regressividade na proteção social quando a expectativa de solidariedade da sociedade tende a centrarse irrealisticamente na família.

Por esta razão, adotamos aqui uma perspectiva de análise do grupo familiar no quadro geral da política social, acreditando que "a questão da família não aparece mais - se algum dia apresentou-se assim - como uma questão que deve ser tratada no plano setorial, mas como um componente incontornável da reflexão sobre o EstadoProvidência" (Martin, 1997, p. 358). 


\section{Bibliografia}

BARG, L. Los vínculos familiares: reflexiones desde la práctica profesional Buenos Aires, Argentina: Espado Editorial, 2003.

BATTAGLIOLA, F. Des aides aux familles aux politiques familiales 1870-1914. Genèses, Paris, n. 40, p. 144-161, sept. 2000.

BIANCO, L. Sotto lo stesso tetto. In: ARANCIO, S. (a cura). Politiche perle famiglie. Torino: Gruppo Abele, 1995.

BOSCHETTI, I. Seletividade e residualidade na Política de Assistência Social. In: CARVALHO, D.; SOUZA, N. H. B.; DEMO, P. (Org.). Novos paradigmas da Política Social. Brasília: Ocidental, 2002.

CAMPOS, M. S. Democratização e desigualdade social no Brasil: notas sobre algumas implicações profissionais. Serviço Social e Sociedade, São Paulo, v. 19, n. 57, p. 9-27, jul. 1998.

. Direitos Sociais no Brasil hoje. Revista Estudos, Goiânia, v. 26, n. 4, p. 547-557, out/dez 1999.

DONATI, P. Famiglia, soggetti e politiche sociali. I/ Bambino Incompiuto, Roma, n. 2, p. 9-24, 1996.

DE MARTINO, M. Políticas sociales y família: Estado de bienestar y neoliberalismo familiarista. Fronteras, Montevideo, Uruguay, n. 4, p. 103114, set. 2001.

ESPING-ANDERSEN, G. Social foundations of postindustrial economies. New York: Oxford University Press, 1999.

. The three worlds of Welfare Capitalism. Cambridge: Polity Press, 1990.

EUROSTAT. Les femmes et les hommes dans 1'Union Européenne: portrait statistique. Luxembourg: Office des Publications Officielles des Communautés Européennes, 1995.

FARGION, V. Timing and the development of Social Care Services in Europe. West European Politics, special issue on Recasting European Welfare States, v. 23, n. 2, april 2000.

FERREIRA, I. Boschetti. Assistência Social: os limites à efetivação do direito. Katálysis, Florianópolis, n. 4, p.65-74, maio, 1999.

FERRERA, M. // Welfare State in Itália: sviluppo e crisi in prospettiva comparata. Bologna, Itália: II Mulino, 1984.

FOLHA DE SÃO PAULO, São Paulo, 30 out. 2002.

FONSECA, A. M. M. Família e política de renda mínima. São Paulo: Cortez, 2001. 
JELIN, E. La tensión entre el respeto a la privacidad y las responsabilidades del Estado. In: FASSLER, C. et al. (Org). Género, família y políticas sociales. Montevideo: Trilce, 1997.

LENOIR, R. Family policy in France since 1938. In: AMBLER, J. S. (Ed.), The French Welfare State: surviving social and ideological change. New York: New York University Press, 1991. p. 144-185.

LEWIS, J. Introduction. In: Politique familiale et place de la famille. In: MIRE. Comparer les systèmes de protection sociaie en Europe du Sud. Paris: MIRE, 1997. v. 3: Rencontres de Florence, p. 329-339.

Gender and welfare regimes. In: LEWIS, G.; Recontre de Florence; CLARKE, J. (Ed.). Rethinking social policy, London: Sage, 2000.

MARSHALL, T. H. Política social. Rio de Janeiro: Zahar, 1967.

MARTIN, C. Protection sociaie et protection par la famille: quelques spécificités? In: MIRE. Comparer les systèmes de protection sociaie en Europe du Sud. Paris: MIRE, 1997. v. 3: Rencontres de Florence, p. 341-361.

MIOTO, R. C. T. Novas propostas e velhos princípios: subsídios para a discussão da assistência às famílias no contexto de programas de orientação e apoio sócio-familiar. Fronteras, Montevideo, p. 94-102, sep. 2001.

PEREIRA, P. A. P. Desafios contemporâneos para a sociedade e a família. Serviço Social e Sociedade, São Paulo, n. 48, p. 103-114, 1995.

. Necessidades sociais: subsídios à crítica dos mínimos sociais. São Paulo: Cortez, 2000.

PIERSON, P. Three Worlds of Welfare Research. Comparative Politicai Studies, v. 33, n. 6/7, p. 791-821, AugVSept. 2000.

PRUZAN, V. B. Politiche e modelli familiari in Danimarca. In Politiche per le famiglie. Quaderni de Animazione e Formazione. Animazione Sociaie. Pp. 31-36. Torino: Edizione Gruppo Abele, 1995.

ROCHA, M. G. de la. The erosion of a survival odel : urban household responses to persistent proverty. In: GENDER, PROVERITY AND WELLBEING: INDICATORS AND STRATEGIES, 1997, Kerala. Session IV: Social services, poverty and the reproductive crisis: the urban dimension. Trivandrum, Kerala, 24-27 novembro 1997. (Mimeogr.).

ROCHA, M. G. de la; GRINSPUN, A. Private adjustments: households, crisis and work. In: GRINSPUN, A. (Ed.). Choices for the poor: lessons from national poverty strategies. New York: UNDP, 2001. 
SARACENO, C. Mutamenti delia famiglia e politiche sociali in Itália. Bologna, Itália: II Mulino, 1998.

. The Ambivalent Familism of the Italian Welfare State. Social Politics, Illinois, 60-82, Spring, 1994.

SCHULTEIS, F. La famille: une catégorie du droit social? Une comparaison franco-allemande. In: MIRE. Comparer les systèmes de protection sociale en Europe. Paris: MIRE, 1996. v. 2: Rencontres de Berlin, p. 203-234.

SGRITTA, G. B. Famiglia, mercato e Stato. Milano: Franco Angeli, 1988.

SILVA, M. O. S. A política social brasileira no século XXI: redirecionamento rumo aos Programas de Transferência de Renda. In: CARVALHO, D.; SOUZA, N. H. B.; DEMO, P. (Org.). Novos paradigmas da política social. Brasília: Ocidental, 2002.

VALIENTE, C. Le rejet de l'héritage autoritaire: la politique de la famille en Espagne. In: MIRE. Comparer les systèmes de protection sociale en Europe du Sud. Paris: MIRE, 1997. v. 3: Rencontres de Florence, p. 389-411.

VASCONCELOS, P. Redes de apoio familiar e desigualdade social: estratégias de classe. Análise Social, Lisboa, v. 37, n. 163, p. 507-544, verão, 2002.

YAZBEK, M. C. Política social: assistência social e filantropia. In: CARVALHO, D. B. B. de (Org.). Novos paradigmas da Política Social. Brasília: UNB, Departamento de Serviço Social, 2002. 